\title{
PREPARING SCHOOL GRADUATES TO INTEGRATE INTO THE WORLD OF TECHNOLOGICAL INNOVATION, SOCIAL AND ECONOMIC CHANGES, AND GLOBALIZATION: THE ROLE OF TEACHING TECHNOLOGY AND ENGINEERING
}

\section{MOSHE BARAK}

D. Sc., Professor

Ben-Gurion University of the Negev, Israel

mbarak@bgu.ac.il

KEYWORDS: COMPUTATIONAL THINKING, PROJECT-BASED LEARNING, TECHNOLOGY AND ENGINEERING EDUCATION.

For citation: Barak M. (2019), Preparing School Graduates To Integrate Into The World Of Technological Innovation, Social And Economic Changes, And Globalization: The Role Of Teaching Technology And Engineering, Globalization And Business, №7, pp. 16-23. https://doi.org/10.35945/gb.2019.07.002

\section{INTRODUCTION}

Technological innovation, social and economic changes, and accelerating globalization are constraining the education system to prepare school graduates to integrate successfully into the rapidly changing world. The OECD (2018) report entitled The Future of Education and Skills 2030 states that the future is uncertain and we cannot predict it; but we need to be open and ready for it. Children entering the education system today will be young adults by 2030. Schools have to prepare them for jobs that have not yet been created, for technologies that have not yet been invented, and to solve problems that have not yet been anticipated. To navigate through such uncertainty, students will need to develop curiosity, imagination, resilience and self-regulation. They will need to respect and appreciate the ideas, perspectives and values of others, cope with failure and rejection, and move forward in the face of adversity.

Heinrich, Bhattacharya, and Rayudu, (2007) emphasize that rapid technological change, increasing globalization and a changing world of employment with multiple roles during oness professional life are necessitating a change from knowledge to learning societies. Full participation requires lifelong learning skills, meaning the ability to solve problems, work both independently and in a team, communicate effectively in different formats, and selfdirect oness learning and professional development needs.
What tools do schools have in order to deal with this challenge? In the past, technology education had often been associated with crafts or vocational education for low-achieving students. However, in recent years, leading countries at the forefront of science and technology around the world have been making efforts to include the teaching of innovative subjects in technology and engineering as an integral part of the curriculum for all students in K-12 education. Along with teaching basic subjects such as the humanities, languages, mathematics and science, schools are expected to expose all students to new technologies, impart knowledge and skills to them to use these technologies effectively, and foster their motivation to integrate into the world of research and innovation in technology and engineering.

The present paper aims at highlighting some directions for technology and engineering education in K-12 schooling intended to meet the challenges mentioned above based partially on the experience obtained in schools in Israel and in other countries.

\section{INTERDISCIPLINARY VIEW OF TECHNOLOGY AND ENGINEERING EDUCATION}

Educators today are increasingly aware of the importance of imparting an interdisciplinary view of 
technology and engineering to students, as illustrated in Figure 1.

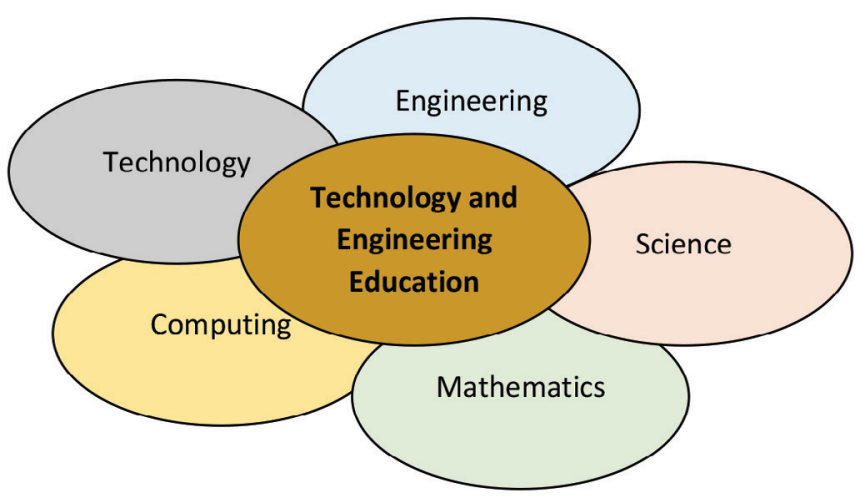

Figure 1: Interdisciplinary view of technology and engineering.

The five aspects illustrated in Figure 1 are not discrete but overlap one another to a certain extent. For example, technology is often described as the field of knowledge and experience through which people change the environment to meet their needs and desires. Engineering is the division of technology that uses science and mathematics for design and problem solving. Computing is a central aspect of developing new technological artefacts and services. These five components are often 'hidden' in projects that the students do, and it is necessary to guide the learners to address these aspects directly in their project design, construction, testing and documentation, as demonstrated in the following examples.

Example 1: addressing aspects of mathematics, physics and computational thinking in robotics

Robotics is one of the most common learning environments in technology and engineering. Barak and Assal (2018) present a case in which students explore the velocity of a robot by marking the distance the robot moves on the floor every five seconds. They use a spreadsheet to draw a graph of the distance $X(\mathrm{Cm})$ depending on the Time $(\mathrm{sec})$ and calculate the robot's average velocity $v(\mathrm{~m} / \mathrm{s})$, as illustrated in Figure 2.

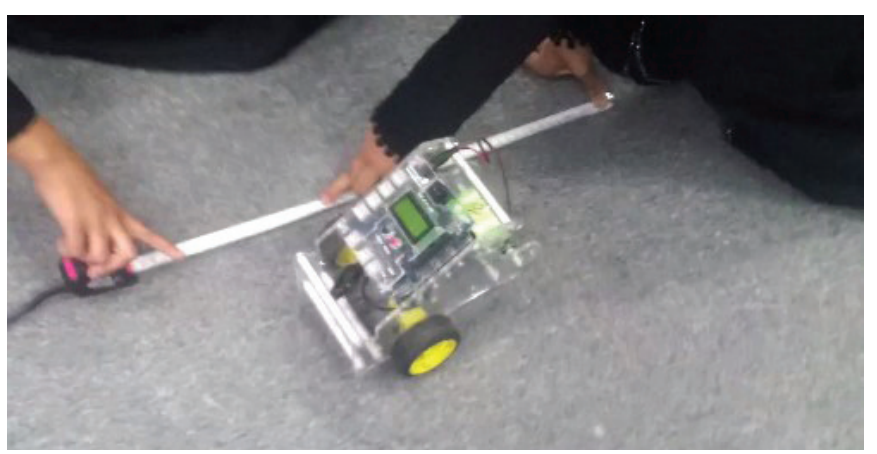

Figure 2: Robotics, STEM and computational thinking: students explore a robot's velocity by measuring the distance $X(\mathrm{Cm})$ the robot moves on the floor over Time (sec).

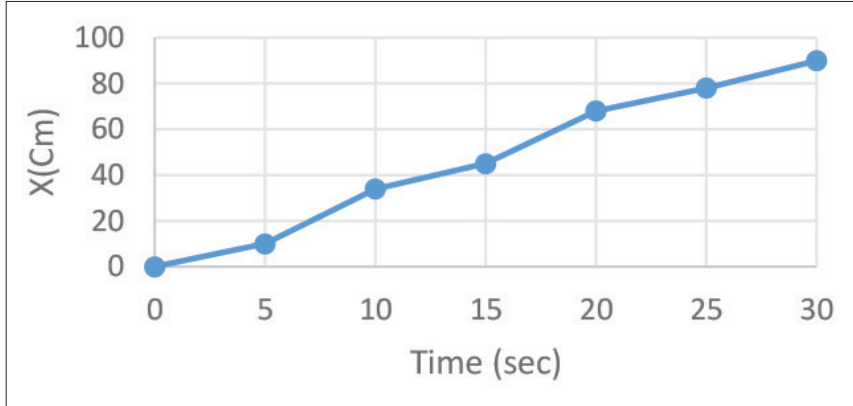

In the example described in Figure 2, the students deal with concepts of technology, physics, mathematics and computational thinking, including programming the robot and using the computer for data presentation and analysis. In the study from which this example was taken (Barak \& Assal, 2018), the students liked this activity because it related to what they had learned in other subjects in school.

Technological aspects of projects in robotics include the concepts of feedback and control, sensing, amplification and optimization. According to Yadav, Hong and Stephenson (2016), computational thinking (CT) refers to exposing students to computing ideas and principles within the context of the subject areas they are already learning, for example, mathematics, science, technology or the humanities. Wing (2006) defined computational thinking as "solving problems, designing systems, and understanding human behavior by drawing on concepts fundamental to computer sciences." It is important to note that the concept of CT is not just restricted to the teaching of computer science or programming, but also to the use of principles or tools from the computer world for investigation, planning or problem solving. For example, in a project on temperature control in a greenhouse, students can use a temperature sensor connected to a computer to store information on temperature changes in the greenhouse over 24 hours and analyze these data to design an adequate airconditioning system. Let us see two additional examples of teaching engineering and technology focused on fostering computational thinking

\section{Example 2: teaching computer-controlled systems}

Hacker (2017) asserts that a sound pedagogical approach for fostering computational thinking would guide students in revisiting computer science (CS) and computational thinking (CT) concepts in both physical world contexts, for example, robotics and computer control, and virtual world contexts, for example, game design. In the past decade, we have witnessed the rapid development of advanced, easy-to-use inexpensive microcontrollers such as the Arduino, together with sensors and devices for measuring and controlling physical variables such as temperature, humidity, light and sound. This has made it possible for teachers and students to design sophisticated control systems with only basic electronics or programming knowledge. For example, Barak (2018) presented the case 
of two Israeli high school students who developed a system to prevent forgetting a baby in a car. The system uses an ultrasonic sensor and Arduino microcontroller to identify whether there is a baby in the baby's car seat. In case of emergency, the microcontroller: (1) opens the car windows automatically; (2) sounds an alarm; and (3) sends a signal to the car owner via a GSM cellular card.

This example demonstrates remarkable options of experiencing problem solving through project work in a computerized environment, from choosing the conceptual solution to the problem, to troubleshooting specific problems in the system's components or software. Students working on non-computerized electronics projects in contrast are more likely to progress along a linear path: planning, constructing, troubleshooting and improving.

\section{Example 3: learning with Lego Mindstorms robots}

A useful platform for fostering computational thinking in problem solving is robotics. Among the most popular educational robots is the Lego EV3 robot, which comes with a rich set of sensors, including a touch sensor, a light color sensor, an ultrasonic sensor and a gyro, as illustrated in Figure 3.

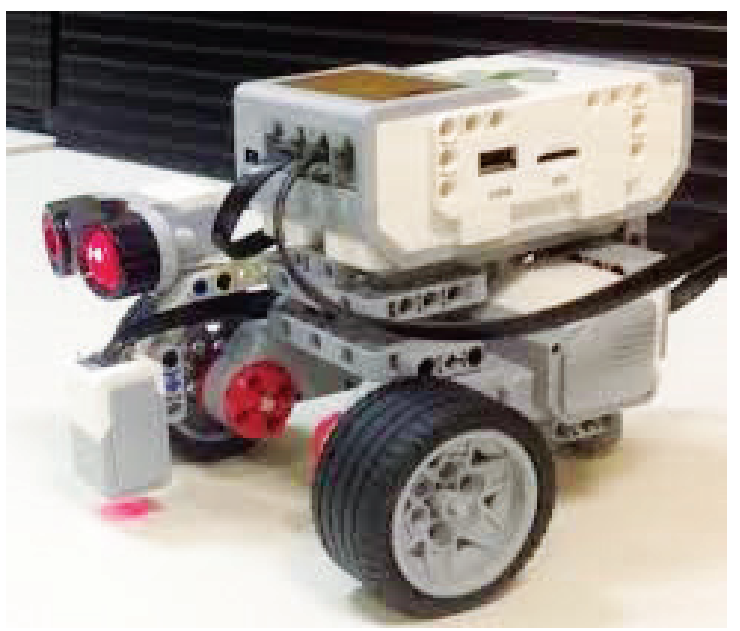

Figure 3: Lego Mindstorms EV3 robot, including a light color sensor and an ultrasonic sensor.

The programming of the EV3 Logo robot consists of:

- Action blocks that control motor operation;

- Flow blocks, for example, loops and conditions;

- Sensor blocks;

- Data operation blocks.

Figure 4 shows a typical EV3 robot program that includes two motor blocks, a sensor block and a loop. This is one of the most sophisticated and popular educational robotic educational systems, although it is quite expensive for schools.

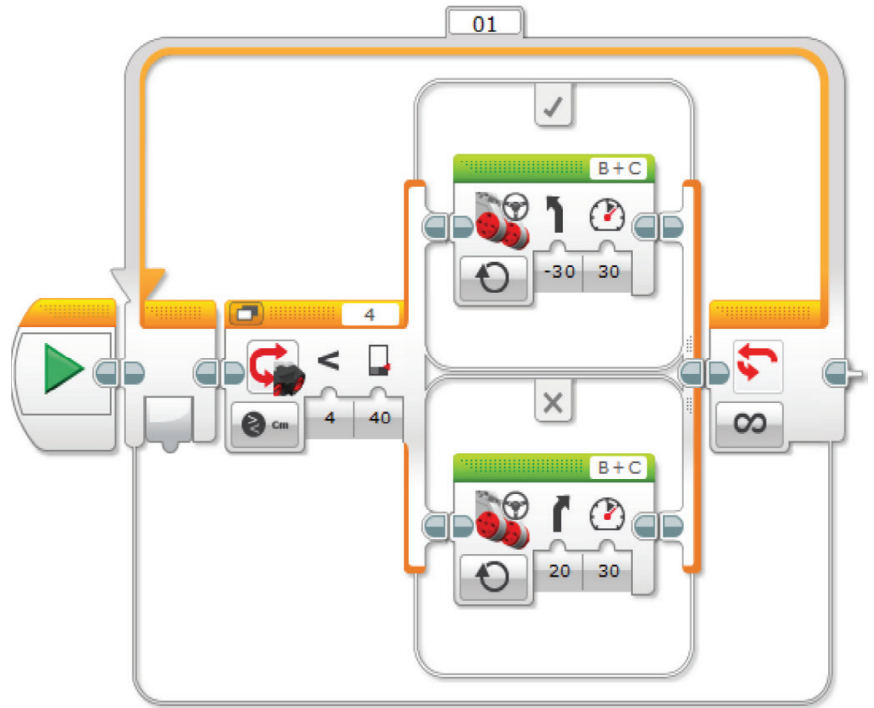

Figure 4: A typical Lego EV3 robot program.

Example 4: learning programming and control concepts with Scratch

A common environment for teaching computational thinking and problem solving is the free Scratch educational programming language, which was developed at MIT and released in 2013. Scratch has been translated into 70+ languages and is used in homes, schools and after-school clubs in almost every country around the world. In its basic version, Scratch is oriented at controlling the movement of a virtual spirit, for example, a cat, on a working surface. There are many programming blocs, such as action, flow, control, sensing and mathematical operations, which are similar to the EV3 programming method. Recently, Scratch has been used increasingly to control objectives in the physical world, for instance, activating motors, reading data from sensors, controlling the Arduino microcontroller or the Lego EV3 robot, as seen in Figure 5.

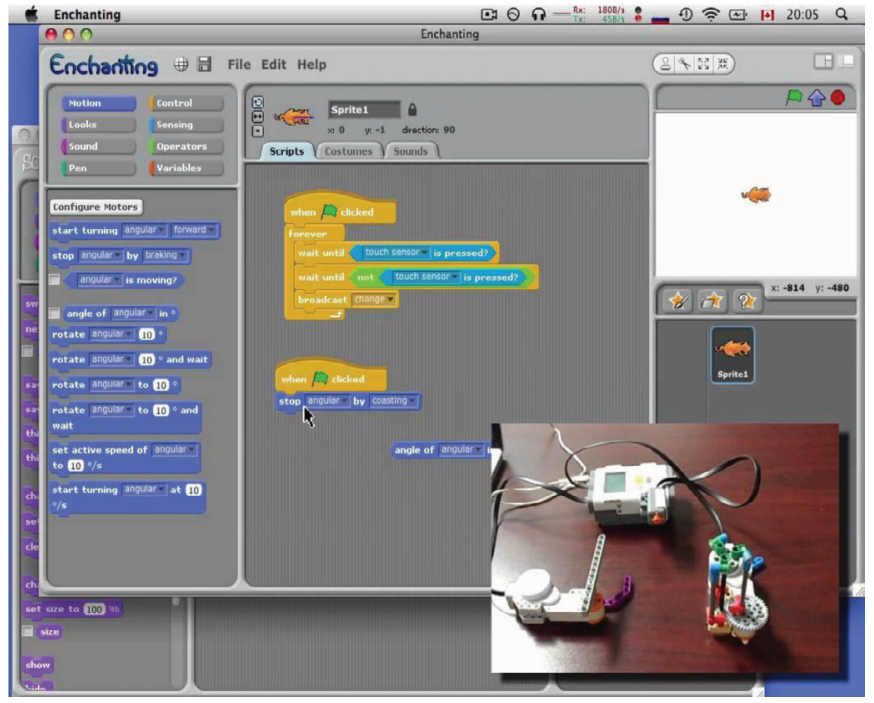

Figure 5: Using Scratch to control a Lego NXT robot. 


\section{Example 5: robotic control by Python}

Molins-Ruano, Gonzalez-Scaristan and Gracia-Saura (2018) point out that although Scratch is a great tool for new young learners, the design and default spirit of Scratch might be considered childish and could discourage high school or college students from using it. These researchers developed a sophisticated robot called Tortoise, shown in Figure 6.

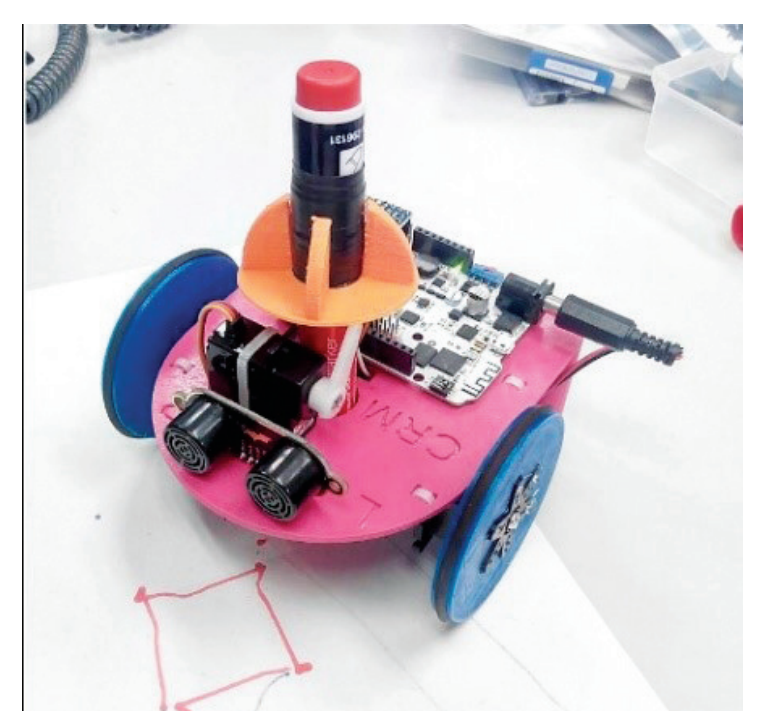

Figure 6: The Tortoise robot.

According to the authors, Tortoise is based on the Arduino microcontroller and simple mechanical components that schools can produce themselves using a 3D printer. The total cost of Tortoise, including a set of sensors, is less than $\$ 100$. The developers call this robotic system PHOGO and show that it can be controlled by the Python programming language, which was ranked the fourth most popular language after Java, $\mathrm{C}$ and $\mathrm{C}++$.

Programming the robot by Python is text-based, and the functions available to the students are similar to the ones in the historical Logo programming environment developed at MIT in the 1970s. For example:

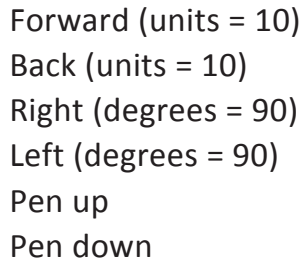

The students can start learning to program the robot by writing a simple code in Python and gradually advance to coping with more sophisticated tasks. While working with Scratch or programming, the LEGO robots can be suitable for students from the age of 10; programming the PHOGO robot using Python may be suitable for older students, for example, those aged 14.

Example 6: teaching concepts of digital image processing

Image processing is one of the most fascinating subjects in the field of computer science and technological applications. Although professional image processing uses advanced mathematics and programming, we can teach basic concepts of image processing to young children (for example, junior high school students), as was observed in a course developed at Ben-Gurion University of the Negev (Barak \& Asad, 2012).

Figure 7 shows that in presenting a black-and-white image, which is actually composed of gray levels, we can use a format of 8-bit digital data that distinguishes between 256 brightening levels from 010 (full black) to 25510 (full white).

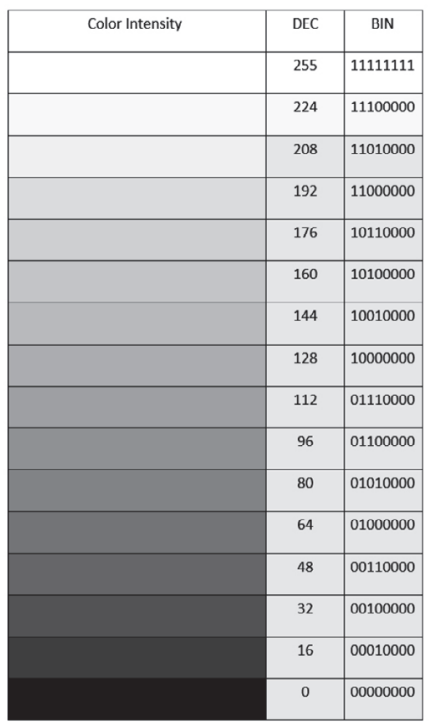

Figure 7: Representation of 256 brightness levels from black (010) to white (25510).

Figure 8 shows an example of 'digitizing' a picture to $12 \times 16$ pixels, assigning a number (brightness level) to each pixel, and finally presenting the entire picture in a matrix of $12 \times 16$ numbers. In other words - the picture is represented by numbers! It is worth mentioning that in real life, for example, on a computer screen or a digital camera, we often use much higher resolution, such as 1440 x 1080 pixels.
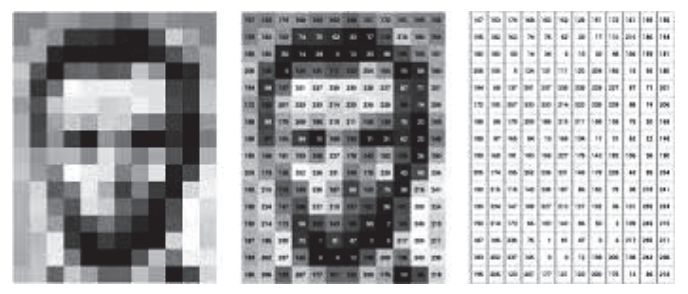

Figure 8: Image representation by $12 \times 16$ pixels at brightness levels 0-255. 
So far we have seen the method of digitizing a blackand-white image. How is a color picture digitized? In a color picture, each pixel gets a different color. From physics, we know that any color could be created by a composition of the three basic colors of red, green and blue (RGB). Figure 9 illustrates an example of creating an orange pixel through the composition of red=255, green $=178$ and blue $=102$. A colored picture of $\mathrm{n} \times \mathrm{m}$ pixels is created by a composition of three matrixes of the same dimension representing the $\mathrm{R}, \mathrm{G}$ and $\mathrm{B}$ colors.
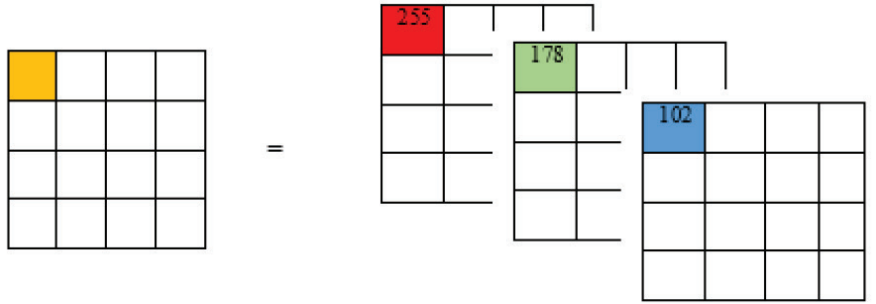

Figure 9: An orange pixel created by the red, green and blue (RGB) colors.

In summary, when we take a picture with our digital camera, we are actually saving a file of numbers, and computers can handle numbers very well. For example, if we want to increase the brightness of an entire image, we will add a number, for example, 20, to the brightness level of each pixel.

\section{FACIAL RECOGNITION}

Facial recognition is one of the most interesting image processing applications (Midrak, 2018). However, how can we use a digital image to identify a person's face? Following is a simple method for facial recognition that was learned successfully by junior high school students (Barak \& Asad, 2012). Figure 10 shows that for facial recognition, we can measure eight parameters from the picture of a face:
be - distance between eyes
bn - distance between nostrils
mw - mouth width
en - distance between eyes and nose
$\mathrm{nm}$ - distance between nose and mouth
mh - mouth width
w - total width
$\mathrm{h}$ - total height

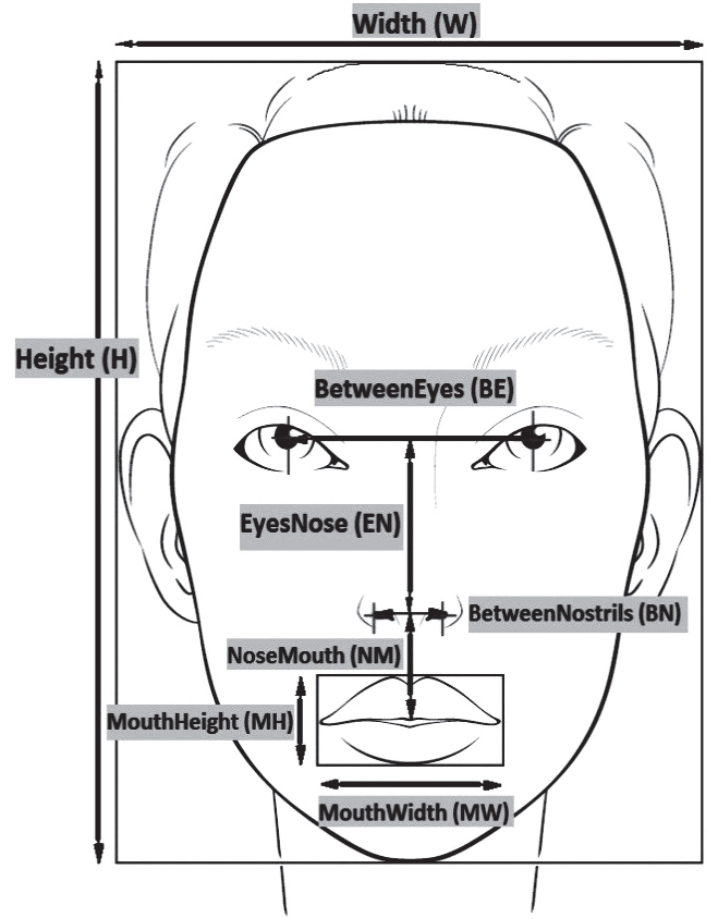

Figure 10: Eight parameters used for facial recognition.

Let us assume that we have values of the eight parameters for two faces:

Face $1=\{$ be 1, bn $1, \mathrm{mw} 1, \mathrm{en} 1, \mathrm{~nm} 1, \mathrm{mh} 1, \mathrm{w} 1, \mathrm{~h} 1\}$

Face $2=\{\mathrm{be} 2, \mathrm{bn} 2, \mathrm{mw} 2, \mathrm{en} 2, \mathrm{~nm} 2, \mathrm{mh} 2, \mathrm{w} 2, \mathrm{~h} 2\}$

Since the faces could be of different sizes, we normalize the six parameters $\mathrm{b} 1$ to $\mathrm{mh}$ by dividing each one by total width $w$ or total height $h$, respectively. We get six normalized parameters $a, b, c, d$, e and f for each picture, as seen in Equations 3 and 4.

$$
\begin{aligned}
& a 1=\frac{b e 1}{w 1} b 1=\frac{b n 1}{w 1} c 1=\frac{m w 1}{w 1} d 1=\frac{n m 1}{h 1} \text { e1 }=\frac{m h 1}{h 1} f 1=\frac{e n 1}{h 1} \\
& a 2=\frac{b e 2}{w 2} b 2=\frac{b n 2}{w 2} c 2=\frac{m w 2}{w 2} d 2=\frac{n m 2}{h 2} \text { e2 }=\frac{m h 1}{h 2} f 2=\frac{e n 2}{h 2}
\end{aligned}
$$

In this process, a vector of parameters a-f represents each facial picture.

The last step is calculating the difference $D$ between the vectors of two faces by the formula presented in Equation 5.

$D=\sqrt{(a 1-a 2)^{2}+(b 1-b 2)^{2}+(c 1-c 2)^{2}+(d 1-d 2)^{2}+(e 1-e 2)^{2}+(f 1-f 2)^{2}}$

Equation 5 shows the calculation of the 'Euclidean distance' between two vectors of six dimensions each that can be explained as an extension of the Pythagoras theorem for calculating the diagonal in a straight triangle. Students can perform the process described above using a spreadsheet. 
In class, the students worked in pairs, took photos of themselves, and manually measured the eight parameters be, bn, mw, en, $\mathrm{nm}, \mathrm{mh}, \mathrm{w}$, h of their photos, as illustrated in Figure 11. They entered the data into a simple computer program that created a database of vectors for all students' faces in the class. To identify a student, the program calculates the difference $D$ between the 'unknown' picture and all the pictures stored in the class database. The case of the smallest $D$ identifies the desired image.

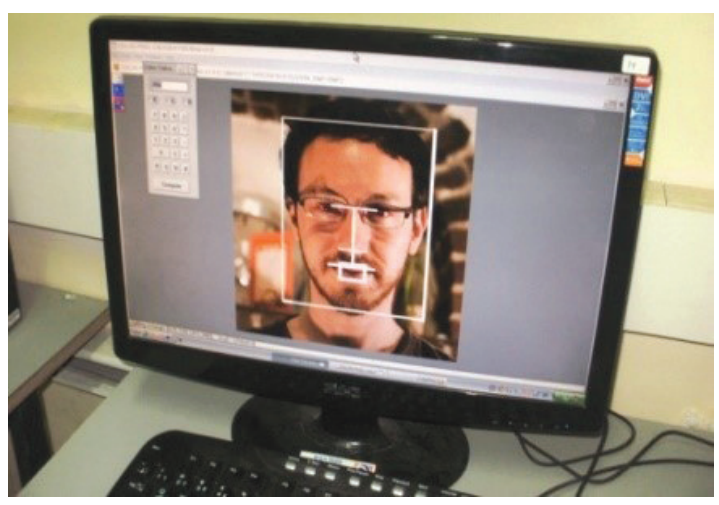

Figure 11: Measuring the eight facial parameters.

In an era when children are growing up with mobile phones, tablets and computers, technological education must be integrated into the digital environment and realize the inherent potential of computerized technologies to develop students> problem-solving and creative thinking abilities.

\section{APPLYING PROJECT-BASED LEARNING IN SCHOOL: THE P3 TASK TAXONOMY}

In technology education, educators often use the term project-based learning, which implies that at the end of the learning process, students build a product or technological system that meets the needs and aspirations of human beings. Project-based learning (PBL) is a constructivist approach that requires a small student group to take responsibility for their learning. This instructional method aims at engaging students in solving reality-based problems, encouraging them to become active, independent and collaborative learners (Mioduser \& Betzer, 2008; Blumenfeld et al., 1991; Savery, 2006). Project-based learning develops students' critical thinking and problem-solving skills, and gives them experience in applying these skills to realworld situations. Project-based learning is one of the tools education has in order to prepare students to integrate into a world in which the vast majority of business organizations are not bureaucratic but rely instead on work teams, shared decision making and a great deal of risk-taking in the effort to compete in the global market (Nordgren, 2002). The digital revolution that has been affecting all aspects of our lives, including education, has pushed forward efforts to introduce project-based learning into traditional schooling because students today have access to tremendous resources and tools on the network for investigating scientific and technological issues, suggesting solutions to problems and designing innovative technological systems.

However, despite the wide consensus in the literature about the advantages of PBL over traditional schooling, educators are increasingly aware of the limitations of applying these methods within the regular school context. Kirschner, Sweller and Clark (2006) write about the failure of constructivist-oriented instructional methods such as discovery, problem-based and inquiry-based learning because the notion of minimal guidance during learning does not work. Minimal guided instruction is less effective and efficient than instructional approaches, which place strong emphasis on guiding the student learning process (Hushman \& Marely, 2015). Some supporters of PBL (Hmelo-Silver, 2004; Hmelo-Silver et al., 2007; Savery, 2006) address the limitations of this method, and mention that it is important to tailor the scope and complexity level of assignments to students' prior knowledge and skills, and provide instruction and support in order to reduce the cognitive load and enable students to learn in a complex domain. Dolman et al. (2005) also writes that PBL curricula should consist more of tutor guidance at the beginning through shared guidance of both the students and the tutor, and move to more student guidance at the end.

To address this issue, we developed the P3 Task Taxonomy (Barak \& Assal, 2018), which distinguishes between three levels of student assignments:

- Practice: exercises and closed-ended tasks in which learners know the final solution in advance and can check if they arrived at the correct answer;

- Problem solving: small-scale, open-ended tasks in which students might use different solution methods and arrive at different answers;

- Projects: challenging open-ended tasks in which the students take part in defining the problem, setting objectives, identifying constraints and choosing the solution method;

\section{CONCLUSIONS}

The OECD (2018) report entitled The Future of Education and Skills 2030, mentioned in the Introduction to the present paper, raises two far-reaching questions countries will have to find answers to in order to prepare students to the rapidly changing world characterized by scientific and technological innovation and accelerating globalization: 
- What knowledge, skills, attitudes and values will today's students need to thrive and shape their world?

- How can instructional systems develop knowledge, skills and attitudes effectively?

Throughout this article, we have seen several examples of teaching technology and engineering that could provide partial answers to these questions. One common feature of the examples we have seen is the interdisciplinary approach in teaching science and technology, which combines the learning of concepts in technology, engineering, science, mathematics and computing. A second common feature of these examples is the transition from the traditional chalk-and-board teaching approach to the constructivistoriented project-based learning approach. The challenge for educators is how to gradually make these changes in the subjects we teach and in the instruction method, adapting to the students previous knowledge and their ability to cope with learning challenging interdisciplinary topics independently.

\section{REFERENCES:}

1. Barak, M. \& Asad, K. (2012). Teaching image processing concepts in junior high school: boys' and girls' achievements and attitudes towards technology. Research in Science and Technological Education, 30(1), 81-105.

2. Barak, M. (2018). Teaching electronics: from building circuits to system thinking and programming. In: M. De Vries (Ed.), Handbook of Technology Education, Cham, Switzerland: Springer, 337-360.

3. Barak, M., \& Assal, M. (2018). Robotics and STEM learning: students' achievements in assignments according to the P3 Task Taxonomy - Practice, Problem solving, and Projects. International Journal of Technology and Design Education, 28(1), 121-144, doi:10.1007/s10798-016-9385-9.

4. Blumenfeld, P. C., Soloway, E., Marx, R. W., Krajcik, J. S., Guzdial, M., \& Palinscar, A. (1991). Motivating project-based learning: sustaining the doing, supporting the learning. Educational Psychologist, 26(3 \& 4), 369-398.

5. Dolmans, D. M., de Grave, W., Wolfhagen, I. P., \& van der Vleuten, C. M. (2005). Current perspectives: problem-based learning: future challenges for educational practice and research. Medical Education, 39(7), 732-741.

6. Hacker, M. (2017). Integrating computational thinking into technology and engineering education. Technology and Engineering Teacher, 77(4), 8-14.

7. Heinrich, E., Bhattacharya, M., \& Rayudu, R. (2007). Preparation for lifelong learning using ePortfolios. European Journal of Engineering Education, 32(6), 653-663. https://doi-org.ezproxy.bgu.ac.il/10.1080/03043790701520602

8. Hmelo-Silver C. E., Duncan, R. G., \& Chinn, C. A. (2007). Scaffolding and achievement in problem-based and inquiry learning: a response to Kirschner, Sweller, and Clark 2006. Educational Psychologist, 42(2), 99-107.

9. Hmelo-Silver, C. E. (2004). Problem-based learning: what and how do students learn? Educational Psychology Review, 16(3), 235-266.

10. Hushman C. J., \& Marley S. C. (2015). Guided instruction improves elementary student learning and self-efficacy in science. Journal of Educational Research, 108(5), 371-381.

11. Kirschner, P. A., Sweller, J., \& Clark, R. E. (2006). Why minimal guidance during instruction does not work: an analysis of the failure of constructivist, discovery, problem-based, experiential, and inquiry-based teaching. Educational Psychologist, 41(2), 75-86.

12. Midrak, R. L. (2018). What is facial recognition? Lifewire, September 3, https://www.lifewire.com/how-does-acomputer-recognize-your-face-4154178

13. Mioduser, D., \& Betzer, N. (2008). The contribution of project-based-learning to high-achievers' acquisition of technological knowledge and skills. International Journal of Technology \& Design Education, 18(1), 59-77. https://doiorg.ezproxy.bgu.ac.il/10.1007/s10798-006-9010-4.

14. Molins-Ruano, P., Gonzalez-Sacristan, C., \& Garcia-Saura, C. (2018). Phogo: A low-cost, free and "maker" revisit to Logo. Computers in Human Behavior, 80, 428-440.

15. Nordgren, R. D. (2002). Globalization and education: what students will need to know and be able to do in the global village. Phi Delta Kappan, 84(4), 318-321.

16. Organization for Economic Co-operation and Development (OECD) (2018). The Future of Education and Skills Education 2030 https://www.oecd.org/education/2030/E2030\%20Position\%20Paper\%20(05.04.2018).pdf

17. Savery J. R. (2006). Overview of problem-based learning: definitions and distinctions. Interdisciplinary Journal of Problem-Based Learning, 1(1):9-20.

18. Wing, J. M. (2006). Computational thinking. Communications of the ACM, 49(3), 33-35.

19. Yadav, A., Hong, H., \& Stephenson, C. (2016). Computational thinking for all: pedagogical approaches to embedding 21st century problem solving in K-12 classrooms. Tech Trends, 60(6), 565-568. doi:10.1007/s11528-016-0087-7. 


\section{PREPARING SCHOOL GRADUATES TO INTEGRATE INTO THE WORLD OF TECHNOLOGICAL INNOVATION, SOCIAL AND ECONOMIC CHANGES, AND GLOBALIZATION: THE ROLE OF TEACHING TECHNOLOGY AND ENGINEERING}

\section{MOSHE BARAK}

\section{Sc., Professor}

Ben-Gurion University of the Negev, Israel

mbarak@bgu.ac.il

KEYWORDS: COMPUTATIONAL THINKING, PROJECT-BASED LEARNING, TECHNOLOGY AND ENGINEERING EDUCATION.

For citation: Barak M. (2019), Preparing School Graduates To Integrate Into The World Of Technological Innovation, Social And Economic Changes, And Globalization: The Role Of Teaching Technology And Engineering, Globalization And Business, №7, pp. 16-23. https://doi.org/10.35945/gb.2019.07.002

\section{ABSTRACT}

Technological innovation, social and economic changes, and globalization are forcing the education system to prepare school graduates to integrate successfully into the rapidly changing world. Along with teaching basic subjects such as the humanities, languages, mathematics and science, schools should expose all students to new technologies, impart knowledge and skills to them to use these technologies effectively, and foster their motivation to integrate into the world of research and innovation in technology and engineering. Schools need also to prepare students to integrate into a world in which the vast majority of business organizations are not bureaucratic but rely instead on work teams, shared decision making and a great deal of risk-taking in the effort to compete in the global market. One of the main tools available to schools to achieve these goals is the teaching of subjects in technology and engineering as an integral part of the curriculum from kindergarten to high school. One challenge for technological education worldwide is to change what we have been teaching in the technological class. While in the past, technology education dealt with teaching subjects such as crafts, auto-mechanics or electronics, technology studies today have to focus more on developing students' computational thinking, for example, in the context of computerized control systems and robotics. A second challenge to technological education today is to change how we teach in the technological classroom. We must move from the traditional chalk-and-board teaching method to teaching that develops students' learning skills, for example, project-based learning. In this article, I will elaborate on these issues and present examples of the implementation of these ideas in the Israeli education system. 